\title{
SER MULHER CUIDADORA DE CRIANÇA COM AIDS: COMPREENSÕES EXISTENCIAIS À LUZ DA FILOSOFIA DE BUBER ${ }^{1}$ BEING FEMALE CAREGIVER OF CHILD WITH AIDS: EXISTENTIAL UNDERSTANDING IN BUBER'S PHILOSOPHY SER MUJER CUIDADORA DE NIÑOS CON SIDA: COMPRENSIONES EXISTENCIALES A LA LUZ DE LA FILOSOFÍA DE BUBER
}

\author{
Diego Schaurich², Stela Maris de Mello Padoin ${ }^{3}$
}

\begin{abstract}
${ }^{1}$ Texto extraído da dissertação de mestrado intitulada "Ser familiar cuidadora de uma criança com Aids: compreensões à luz da filosofia de Martin Buber", defendida no Programa de Pós-Graduação em Enfermagem da Universidade Federal do Rio Grande do Sul (UFRGS), em 2007. Apoio financeiro do Conselho Nacional de Desenvolvimento Científico e Tecnológico (CNPq).

${ }^{2}$ Doutorando do Programa de Pós-Graduação da Escola de Enfermagem da UFRGS. Bolsista da Coordenação de Aperfeiçoamento de Pessoal de Ensino Superior (CAPES). Rio Grande do Sul, Brasil.

${ }^{3}$ Doutora em Enfermagem. Professor Adjunto do Departamento de Enfermagem da Universidade Federal de Santa Maria. Rio Grande do Sul, Brasil.
\end{abstract}

PALAVRAS-CHAVE: Enfermagem. Saúde da mulher. Síndrome da imunodeficiência adquirida. Família.
RESUMO: Estudo qualitativo fenomenológico que buscou compreender o que é ser familiar cuidadora de uma criança com Aids, à luz do referencial filosófico de Martin Buber. As informantes foram sete mulheres, selecionadas de forma intencional junto ao hospital-escola de Porto Alegre - RS. A coleta das informações ocorreu entre setembro e outubro de 2006 por meio da entrevista fenomenológica e, para a interpretação, recorreu-se à filosofia hermenêutica. Emergiram cinco unidades de significação. Ser familiar de criança com Aids revela-se um fenômeno existencial complexo de mudanças, cuidados, diálogos e preocupações, na busca por um estar-melhor de ambos, no mundo. Compreende-se este cuidar como fenômeno também complexo, parte da existencialidade da mulher e da comunidade familiar. Ainda, considera-se a possibilidade de valorização da relação inter-humana entre o EU e o TU e do diálogo existencial para o cuidado humanístico.
KEYWORDS: Nursing. Women's health. Acquired immunedeficiency syndrome. Family.

\begin{abstract}
This qualitative and phenomenological study sought to better understand what it is to be a family-member/caregiver of a child with AIDS, according to Martin Buber's philosophy. The participants in the study were 7 women, chosen by an intentional selection criterion from a university hospital in Porte Alegre - RS, Brazil. The phenomenological interviews with participants were carried out between September and October of 2006, and hermeneutic philosophy was applied for data interpretation. According to data analysis, five units of significance emerged. Being a family member of a child with AIDS reveals a complex existential phenomenon of changes, care, dialogues, and concerns in search of being-better of both in the world. We understand that this care is also a complex phenomenon, part of the existentialism of women and the family community. In conclusion, we believe that valuing the interhuman relationship between I-YOU, and the existential dialogue to humanistic caring is possible.
\end{abstract}

PALABRAS CLAVE: Enfermería. Salud de la mujer. Síndrome de inmunodeficiencia adquirida. Familia.
RESUMEN: Estudio de carácter cualitativo fenomenológico, que buscó comprender, según el referencial filosófico de Martin Buber, lo qué es ser familiar cuidadora de un niño con SIDA. Las informantes fueron siete mujeres, seleccionadas de forma intencional, en el hospital-escuela de Porto Alegre - RS. La recolección de las informaciones fue hecha en los meses de septiembre y octubre de 2006, por medio de entrevista fenomenológica, y para su interpretación, se recurrió a la filosofía hermenéutica. Surgieron cinco unidades de significación. Ser familiar de un niño con SIDA se revela un fenómeno existencial complejo de cambios, cuidados y preocupaciones, en la búsqueda por un estar-mejor de ambos en el mundo. Ese cuidar se comprende como siendo un fenómeno también complejo, que forma parte de la existencia de la mujer y de la comunidad familiar. Además, se considera la posibilidad de valorar la relación interhumana entre el YO y el TÚ, y el diálogo existencial para el cuidado humanístico.
Diego Schaurich

Endereço: Rua Otávio Corrêa, 15, ap. 43

90050-120 - Cidade Baixa, Porto Alegre, RS, Brasil

E-mail: eu_diegosch@hotmail.com
Artigo original: Pesquisa Recebido em: 15 de janeiro de 2008 Aprovação final: 23 de julho de 2008 


\section{CONSIDERAÇÕES INICIAIS}

A epidemia do Vírus da Imunodeficiência Humana/Síndrome da Imunodeficiência Adquirida (HIV/Aids) configura um problema de proporções mundiais e, em virtude de, atualmente, a infecção viral disseminar-se entre a parcela mais jovem da população e, especialmente, entre aqueles que apresentam baixos níveis de renda e escolaridade, representa, também, um importante problema de saúde pública. De acordo com o Ministério da Saúde, ${ }^{1}$ foram notificados 474.273 casos de Aids até junho de 2007, sendo 447.481 em adultos e 26.792 em crianças e adolescentes até 19 anos de idade. Apreende-se, ainda dos dados epidemiológicos, o aumento de notificações entre as mulheres e, conseqüentemente, entre os indivíduos menores de 13 anos (Aids pediátrica), sendo a transmissão vertical responsável por $83,4 \%$ dos casos.

Há que se considerar, então, que a epidemia HIV/ Aids, para além de suas questões epidemiológicas, traz novos desafios e implicações ao viver cotidiano das pessoas, em especial, às crianças e suas cuidadoras. Dentre estes, pode-se citar a necessidade de acompanhamento ambulatorial, a submissão a exames diversos, o uso do tratamento anti-retroviral e a complexidade do processo de adesão, a convivência com situações de preconceito e discriminação, dentre outros. Sendo assim, cada vez mais faz-se relevante a realização de pesquisas que objetivem desvelar e compreender os diferentes cenários vividos e compartilhados pelas crianças com Aids e suas cuidadoras, com vistas a subsidiar o desenvolvimento de um cuidado que se quer humanístico..$^{2-3}$

Portanto, este estudo tem sua gênese ao conviver existencialmente com as famílias que se encontram lançadas no mundo com o HIV. Ele foi concebido em virtude de uma necessidade percebida ao estar no face-a-face com os familiares que cuidam de crianças com Aids e que, também, precisam ser cuidados. ${ }^{4}$ Em virtude disso, buscouse compreender o que é ser familiar cuidadora de uma criança com Aids, tendo por fundamentação o referencial filosófico de Martin Buber. ${ }^{5-7}$

\section{CAMINHO METODOLÓGICO}

Trata-se de um estudo qualitativo com abordagem fenomenológica, o qual permitiu ao pesquisador tomar o fenômeno como essencial, visando compreendê-lo em sua totalidade e complexidade a partir das vivências e experiências como ser-no- mundo e ser-no-mundo-com-o-outro, em dado tempo e espaço compartilhados.

Nesse sentido, seu intuito não é medir, quantificar ou controlar o contexto vivido pelo ser humano, mas captá-lo e apreendê-lo, subjetiva e objetivamente, para, então, realizar a compreensão e interpretação das vivências e experiências pessoais. A fenomenologia tem a possibilidade de descrição dos fenômenos particulares ou da aparência das coisas, como experiência vivida pelo ser em seu mundo, permitindo um retorno à essência vivida, às coisas mesmas do existir humano. ${ }^{8}$

A pesquisa foi realizada no Ambulatório de Pediatria do Serviço de Pediatria de um hospitalescola no município de Porto Alegre - RS. O mesmo conta com uma equipe médica, uma equipe de enfermagem e serviços de assistência social e psicologia que compartilham informações e conhecimentos visando atender as necessidades de cuidado dos familiares e das crianças que vivem com o HIV ou com Aids. As informantes foram mulheres cuidadoras de crianças com Aids, totalizando um grupo de sete, representadas por quatro mães biológicas, uma mãe adotiva e duas avós que compartilham o mundo da vida com a criança que vive com Aids.

A seleção das familiares ocorreu de forma intencional, de acordo com a sua abertura para o estar-com e seu interesse e disponibilidade de participar da pesquisa. Para tanto, a equipe médica do serviço analisava características da cuidadora (freqüência de acompanhamento ao serviço, saúde mental, uso/abuso de drogas) que estava com a criança no dia da consulta, bem como o histórico da família (estrutura, rede de apoio) e da criança com Aids e, quando compreendiam que estavam de acordo com a proposta do estudo, indicavam ao pesquisador, o qual convidava a familiar a participar da entrevista.

A partir deste aceite e da assinatura do Termo de Consentimento Livre e Esclarecido, iniciava-se a entrevista fenomenológica que possibilitou o encontro vivido e dialogado entre o ser pesquisador e o ser pesquisado, ${ }^{9}$ de modo individual. Nessa abordagem busca-se a linguagem genuína, a fala originária do ser pesquisado, e será esta fala que possibilitará o encontro com o outro e a comunicação com o mundo. Para tanto, é preciso ver e observar sem estar fechado em uma perspectiva causal, interpretar compreensivamente a linguagem do ser pesquisado e perceber sua gestualidade em movimento e como veículo de significações. ${ }^{9}$ 
A questão norteadora no encontro fenomenológico foi: conte-me como é, para você, ser familiar de uma criança com Aids? Para a interpretação das informações utilizou-se a filosofia hermenêutica, ${ }^{10}$ que tem por objetivo des-cobrir, descortinar o sentido primário dos discursos visando buscar compreensões acerca da existência humana e daquilo que está velado. A interpretação seguiu as etapas de; leitura inicial do texto; distanciamento; análise estrutural; identificação da metáfora; e, apropriação. Para o desenvolvimento deste estudo foram asseguradas as questões éticas, conforme prevê a Resolução No 196/96 do Conselho Nacional de Saúde que rege as pesquisas com seres humanos, ${ }^{11}$ tendo sido o projeto aprovado pelo Comitê de Ética em Pesquisa da instituição, parecer $\mathrm{N}^{\circ} .122 / 2006$.

\section{DESVELANDO O EXISTIR DE MULHE- RES CUIDADORAS DE CRIANÇAS COM AIDS}

Serão apresentados os resultados da interpretação compreensiva referente à unidade de significação intitulada desvelando os modos de ser-no-mundo do EU familiar que tem por propósito descrever alguns aspectos da existencialidade de mulheres cuidadoras de crianças com Aids, à luz dos constructos buberianos. ${ }^{5-7}$ Elas desvelaram sentimentos, emoções, possibilidades, dificuldades e necessidades que são compartilhadas com a criança, no mundo. Emergiram, então, as seguintes significações: existencialidade do EU familiar ao conviver com a Aids; vivenciando o medo e as perdas; vivências em comunidade familiar; o EU familiar como um ISSO; e, EU familiar na vivência da aceitação e luta.

\section{Existencialidade do EU familiar ao conviver com a Aids}

Apresenta-se as possibilidades existenciais vividas pelo familiar ao conviver com a Aids, considerando a historicidade de seu ser-no-mundo e os diferentes momentos experienciados ao estarcom o outro e com o mundo. Dos discursos emanaram significações acerca das etapas do viver das cuidadoras, desde a descoberta da infecção pelo HIV na criança (e, muitas vezes, do descobrir-se também) até o momento atual.

Entende-se que as primeiras experiências relacionadas à epidemia no mundo da família são consideradas como um momento difícil. Contudo, com o passar do tempo e uma maior experiência no conviver com o outro que tem Aids, a existencialidade da mulher cuidadora passa a ser considerada normal e da qual se pode extrair algumas lições de vida, como mostra o depoimento de F4.

Eu acho que no início, que eu consegui, comecei, a tratar da minha filha [...] pra mim foi uma etapa muito difícil. Agora eu tô achando que a partir do momento que eu comecei a cuidar dos netos, já pra mim tá sendo uma lição, né, porque eu já tive uma lição da outra (F4).

Desvela-se deste discurso, que a cuidadora significa seu primeiro contato com a experiência de conviver com o outro que é portador do HIV como algo difícil, mas que também possibilita o aprendizado de lições. Daquilo que está en-coberto na fala depreende-se que as experiências familiares em relação ao convívio com a Aids provocam, no princípio, desestruturações pessoais na vida do ser familiar, como se sua existência passasse a não ter mais sentido. Porém, com o compartilhar desta convivência, sua existencialidade passa a ser percebida como normal.

Uma vida normal, né, não basta tu viver, tem que saber viver, se tu não sabe viver com a tua família e com os teus filhos tu nunca vai conseguir, tem que saber viver! [...] Saber viver é tu não pensar na doença, é tu fazer o tratamento e não pensar na doença, sabe, tu ter uma convicção de vida (F5).

Este modo de perceber-se como normal e de significar a convivência com a Aids como algo que faz parte do (saber), viver, revela que o EU familiar quer ser percebido existencialmente como é, para além de sua condição sorológica, do tratamento que realize ou da doença que possua. Esta compreensão vem ao encontro do que o filósofo ${ }^{6}$ considera como duas possibilidades para o ser em sua existência: uma seria a vida a partir do ser, a partir daquilo que se é autenticamente, e a outra a vida a partir da imagem, daquilo que se quer parecer ou como se é percebido pelo outro.

Esta maneira como se é percebido pelo outro se revela importante para a afirmação do EU familiar como existencialidade, uma vez que o EU só existe em função do seu $\mathrm{TU}$, sendo a recíproca também verdadeira. ${ }^{5}$ Há que se considerar, então, que a mulher cuidadora procura ser percebida pelo outro como normal e, para tanto, vivencia as situações de seu dia-a-dia na busca da normalidade, a fim de que seja vislumbrada como existencialmente se manifesta no mundo.

As falas das cuidadoras demonstram o quanto o seu existir pode ser considerado único e singular, mas também que não apresenta muitas diferenças daquele vivido pelo outro. $\mathrm{O}$ modo de 
ser-no-mundo desta mulher é significado de acordo com a sua experiência ao conviver com a Aids, desde a compreensão de que algo mudou até a percepção de voltar a ser normal. Contudo, mesmo expressando-se como semelhante aos outros, a familiar revela que os cuidados, principalmente com o tratamento anti-retroviral, estão presentes em seu cotidiano e são considerados importantes.

Lá em casa a gente não esquece um minuto que ele é portador, uma por causa dos cuidados que a gente tem com ele, dá a medicação, sabe, mas a gente trata assim, assim, eu não tenho dificuldade de, de chegar aqui, se eu não te conheço e de dizer: ele é soropositivo! (F2).

Assim, as cuidadoras acreditam que a descoberta da convivência com a Aids é uma situação difícil, mas a vivência cotidiana revela-se como mais tranqüila. A partir daquilo que foi desvelado, pode-se compreender que ser cuidadora neste contexto é mostrar-se como genuinamente se apresenta ao encontro com o TU criança que vive com Aids buscando a reciprocidade no face-a-face das relações com o outro e com o mundo.

\section{Vivenciando o medo e as perdas}

A mulher cuidadora revela, primeiramente, seu medo, ao conviver com a Aids, uma vez que já teve a experiência de perder pessoas significantes, como pode ser observado no depoimento que segue: eu perdi a outra filha, também, elas morreram, uma morreu quando eu estava fazendo 9 mês de uma, a outra tava se, tava se enterrando, tanto que uma morreu no dia 12 de agosto e a outra morreu no dia 12 de maio. Tu vê se isso aí não é um sofrimento prum pai e uma mãe, o senhor convive com um poblema desses aí e ainda sabe que tá convivendo com duas neta como mesmo poblema $(\mathrm{F} 4)$.

O ser humano tem sentido em virtude de sua existência e este existir como ser-no-mundo é projetado até o seu encontro com o processo de morrer e morte. ${ }^{5}$ No des-cortinar do discurso compreendese que a cuidadora revela seu medo ao conviver com a perda de pessoas que são significantes em sua vida, como as filhas e demais familiares que faleceram em decorrência das complicações da Aids. Este medo ao conviver com as perdas tem reflexo direto na relação EU familiar e TU criança com Aids e no receio de perdê-la.

Compreende-se que o ser humano é um ser mortal, não só no aspecto relacionado a sua existencialidade, mas também na alternância das relações EU-TU (em que o outro é vislumbrado como um igual, um ser de possibilidades) e dos relacionamentos EU-ISSO (em que o outro é considerado apenas mais um, um objeto de uso). ${ }^{5} \mathrm{Ou}$ seja, para o filósofo, o ser humano encontra-se em um constante processo de morrer quando deixa de ser EU e passa a ser TU, ou ainda quando distanciase do encontro autêntico e passa a ser objetivado como um ISSO; o morrer é inerente ao existir do EU e faz parte das vivências em família.

A mulher cuidadora revela sentimentos em relação à criança com Aids, os quais fazem parte e constroem a relação estabelecida no face-a-face do vivido, e acredita que o medo e a dor da perda podem ser caracterizados como situações complexas e difíceis de enfrentar. Este medo de perder o TU criança perpassa o EU familiar desde a descoberta da condição sorológica da mesma (ou a sua própria) até o momento atual, conforme mostra F2.

Eu tinha muito medo de perder ele [criança com Aids], sabe, quando, logo que, que eu descobri que ele tinha [...] tinha gente que dizia que durava dois anos, três anos, tinha gente que dizia que não durava... [silêncio]... eu digo, não pode se. Eu digo: não acredito que Deus vai me dá uma criança pra mim cria e quando tive com cinco, seis anos vai me tira, não pode, não acredito! (F2).

O discurso da familiar revela que o medo de perder a criança com Aids, a acompanha desde que a criança é pequena, sendo que a temporalidade desta é algo incerto na vida do ser familiar. Desvela, também, que, embora algumas informações referentes à epidemia do HIV tragam informações acerca do pouco tempo de vida aos infectados, apóia-se no TU-Eterno (Deus) ${ }^{5}$ para continuar a cuidar da criança; a cuidadora prefere não acreditar nas informações que ouviu falar a fim de manter a sua vida mais próxima daquilo que considera normal.

Sentimentos como tristeza e medo são emanados das vivências das cuidadoras mostrando o significar em relação às possibilidades e ao receio que o EU familiar tem de que o TU criança com Aids venha a morrer. Os sentimentos são possuídos pelo ser humano e estão de acordo com o momento vivido pelo mesmo, de acordo com o seu modo de ser-no-mundo; os sentimentos, ainda, ajudam a aproximar os seres humanos e esta aproximação expõe ao EU a finitude presente no existir do TU que se lhe defronta. ${ }^{5}$

\section{Vivências em comunidade familiar}

As compreensões, os modos-de-ser-nomundo e as expectativas em relação à comunidade familiar, bem como a importância do apoio dela recebido para tornar melhor o vivido ao lado da 
criança com Aids, fazem parte do existir da mulher cuidadora. A comunidade (ou com-unidade) é o lugar de encontro entre um EU e um TU, ou de vários EUs com vários TUs, sendo que há a necessidade de que existam entre os seres humanos constantes relações vivas e recíprocas. ${ }^{7}$

Entende-se que "o ser humano se realiza na comunidade, na relação intersubjetiva do indivíduo com o outro, efetivada pela força da palavra dialógica EU-TU". ${ }^{12: 17}$ Há que se considerar, então, que a família representa uma comunidade e que esta, a partir dos discursos do ser familiar, é percebida a partir de seu modo de ser e organizar-se no mundo da vida, bem como em relação ao apoio compartilhado entre seus membros. A seguir, o modo como a cuidadora F5 descreve sua comunidade familiar como normal.

Tenho uma família... [silêncio]... normal. [...] Eu sou casada, o pai dela também é, todo mundo é, cada um é de um jeito: eu sou explosiva, sou meia louca, meu marido é calmo, mas é um normal de família, sabe (F5).

Ao encontro de como a cuidadora descreve sua existencialidade como normal, há, também, a compreensão de que sua família é "normal". Estas significações projetam-se para além das questões relacionadas à epidemia da Aids e ao fenômeno de conviver com a criança soropositiva para o HIV. No des-cortinar das falas pode-se entender que as famílias são consideradas normais tanto quanto qualquer outra família, independente da condição sorológica de seus membros.

Conjuntamente a esta percepção de normalidade, sentimentos emergem entre os seres que compõem a comunidade, o que é fundamental. Além disso, é preciso que exista uma alternância de relações EU-TU e relacionamentos EU-ISSO para que os seres possam se projetar no mundo de acordo com a maneira que se manifestam e como o outro os percebe. ${ }^{7}$ Neste sentido, os discursos apresentam os sentimentos quando a mulher cuidadora descreve que a família representa tudo para ela.

Mas a minha família é, é uma família tranqüila, sabe [...] é aquela coisa, né, brigam, se amam e são criança, né, uma família tranqüila eu acho que... [silêncio]... é mais importante, né, é a tranqüilidade pra, claro que o dinheiro é importante, mas eu acho que a gente, com tranqüilidade tu consegue tudo, né (F2).

$O$ face-a-face entre o EU familiar e os demais TUs familiares revela-se em descrições de que a família ficou mais unida depois da descoberta da infecção pelo HIV em um de seus membros. Para as informantes, a comunidade familiar é tranqüila e aceita o ser que vivência o estar-com
Aids. Compreende-se, ainda, que é o "entre" que permite a reciprocidade, a disponibilidade de estar-com-o-outro, o diálogo entre os seres, a relação e o aparecimento do amor entre o EU e o TU na esfera da comunidade. ${ }^{5,7}$ A comunidade da família desvela-se ser um mundo importante para a mulher cuidadora, pois é onde as coisas acontecem, onde os seres reconhecem-se mutuamente, independente da doença ou condição sorológica que possuam; é neste nível que se procede a questão da normalidade familiar.

Ao encontro dos discursos anteriores em relação à comunidade familiar, ao seu modo-deser-no-mundo e aos sentimentos que mantêm os seres em comunhão, destaca-se o apoio de um TU para com um EU, e vice-versa, como um fenômeno existencial também importante à relação com o outro. $\mathrm{O}$ apoio revela-se um sentimento que possibilita o estar-melhor da cuidadora.

O apoioé importante na família, se tu não tem apoio tu pode crê que tu, tu vai começa a ti, ti isolar das pessoas porque achando que só tu que tá com aquele problema, né, e não é, são milhares e milhares de pessoas, né (F1).

O apoio aparece como elemento fundamental à relação estabelecida entre a cuidadora e a comunidade familiar, pois possibilita o não isolamento, a ajuda nas situações necessárias, o diálogo entre os familiares, o estar-com o outro que vive com o HIV/Aids e a superação das vivências adversas. Nesta pluralidade de significações atribuídas ao apoio recebido da comunidade familiar, pode-se compreendê-lo como um sentimento de reciprocidade no face-a-face existencial. ${ }^{5}$

$\mathrm{Na}$ com-unidade familiar o estar-com-ooutro propicia o mostrar-se da mulher cuidadora como existencialmente se apresenta, com suas potencialidades, dificuldades e necessidades em ser-no-mundo. Desta maneira, o EU familiar vai mostrando-se ao outro (TU) e ao mundo como existencialidade presentificada, também, pela comunidade familiar a que faz parte. Diante dos modos de ser de sua família, da maneira como a significa e da importância que atribui ao apoio dela recebido, a mulher cuidadora vai desvelando que as vivências e experiências em relação à criança com Aids podem ser expressas por expectativas, possibilidades e necessidades.

\section{EU familiar como um ISSO}

O modo de ser-no-mundo da mulher cuidadora é também desvelado ao descrever sua existencialidade nas proximidades do que se 
considera o mundo do ISSO. ${ }^{5}$ Ao referir o distanciamento do outro causado pela discriminação e ao revelar as maneiras como percebe o preconceito na comunidade externa (escola, bairro, entre outras) ao estar no mundo convivendo com uma criança com Aids, a cuidadora revela sentir-se um ISSO, usado, experimentado e objetivado no relacionamento por um outro EU.

Destaca-se que o relacionamento EU-ISSO não é entendido como algo ruim ou negativo; ao contrário, entende-se que é um dos muitos modos que o ser humano tem de manifestar-se com o outro e no mundo, e que a alternância das duas palavras-princípio é fundamental ao seu existir. ${ }^{5}$ Ainda, o filósofo afirma que, pela fugacidade da relação EU-TU, o mundo do ISSO é experienciado pelo ser humano na maior parte de seu tempo. Contudo, para fins desta interpretação, optou-se por considerar o familiar como um ISSO quando vivencia o preconceito emanado pelo EU.

A mulher cuidadora, nesta compreensão, deixa de ser um EU que expressasse de forma autêntica e genuína no mundo, e passa a ser um ISSO que é objetivado de acordo com o olhar lançado pelo EU. Este entendimento pode ser significado pela familiar a partir das descrições que revelam as dificuldades e necessidades vividas ao experienciar o preconceito existente em relação à doença e que faz parte de seu mundo da vida, como um modo de distanciamento do outro.

Às vezes as pessoas se enganam com a aparência, sabe, tu conhece aquela pessoa e tu acha que aquela pessoa é perfeita, mas tu não sabe, entendeu. Não tá escrito na testa que tu é HIV positivo (F1).

Para a mulher cuidadora de uma criança com Aids o preconceito projeta-se em sua existencialidade como uma maneira de distanciamento em relação ao TU, quando, então, prefere manter-se restrita à comunidade familiar. O preconceito existe mesmo que as pessoas não aparentem ser portadoras do HIV ou doentes de Aids, pois não é algo que está "escrito na testa". Percebe-se, neste sentido, que o preconceito é compreendido como um limitador da vida da cuidadora de crianças com Aids.

A relação inter-humana EU-TU, por ser dialogal, requer o consentimento da alteridade do outro como ser de presença e como autenticamente se apresenta ao encontro; já o mundo do ISSO considera o outro de acordo como o EU quer percebê-lo. ${ }^{5-6}$ Por isso, o preconceito pode ser entendido como uma forma de relacionamento EU-ISSO, ou seja, a tentativa de imposição de opiniões e atitudes aquele que se lhe defronta ao EU, visando objetivá-lo no relacionamento instituído e, assim, fazê-lo apenas mais uma coisa entre coisas, um reflexo do olhar do EU em experimentação.

Pode-se perceber que a mulher cuidadora, para além de significar o preconceito como um distanciamento dos outros seres em função de conviver com uma criança que tem Aids, preferindo, muitas vezes, manter sigilo, também vivencia este preconceito na comunidade externa, conforme o discurso que segue.

Tem muita gente às vezes não precisa saber, né, como o doutor falo. Ee é isso que eu acho, ah, eu acho que as pessoas pegam pra comentário, né, invés de pegar e vim te ajudar, não vão vim, então eles pegam e vêm pra comentários, né (F3).

Assim, para não ser percebido pelo outro como um ISSO o familiar prefere omitir a condição sorológica da criança e, conseqüentemente, a própria história familiar, uma vez que a maior parte das crianças é infectada pela transmissão vertical; com isso, acredita que sua existencialidade torna-se mais próxima da normalidade. Ainda, a cuidadora compreende que o interesse do outro é especulativo e depreciativo, servindo apenas para "comentários", e não para auxiliá-la na vivência e convivência com a epidemia da Aids.

Sendo assim, a mulher cuidadora prefere manter segredo em relação a sua soropositividade para o HIV e a da criança, restringindo tal informação à comunidade familiar (em alguns casos) e à equipe de saúde. Este modo-de-ser-nomundo possibilita ao familiar evitar, muitas vezes, situações complicadas e difíceis em que vivencia e experiência o preconceito. Para sair da posição de ISSO no relacionamento objetivante, a familiar procura manter sigilo em relação a soropositividade para o HIV.

\section{EU familiar na vivência da aceitação e luta}

Apresenta-se o modo-de-ser-no-mundo da mulher cuidadora na vivência da aceitação e luta ao conviver com o TU criança que tem Aids. Sua existencialidade revela-se marcada por momentos em que aceitar a situação cotidiana é fundamental para que possa continuar lutando a fim de estar-melhor no mundo e possibilitar uma vida mais autêntica à criança que experiencia a infecção pelo HIV.

A aceitação manifesta-se como sentimento importante ao existir da cuidadora, tanto em relação a sua condição sorológica quanto a da criança, uma vez que propicia conviver com as potencialidades e com as limitações que se manifestam no face-a-face 
com o outro, no mundo. Todo e qualquer sentimento expresso e manifesto pelo ser humano configura uma maneira de ser e estar no mundo da vida; os sentimentos são possuídos pelos seres humanos, e são, juntamente com a palavra proferida, um meio de adentrar à relação EU-TU e ao relacionamento EU-ISSO. ${ }^{5-6}$ Este sentimento de aceitação faz parte da existencialidade da familiar.

Eu aceitei, né, tem muitas pessoas que não aceitam, né, então eu tenho duas crianças com poblema e eu com poblema, né, e eu tenho mais dois filhos que não têm o poblema, e mais o meu marido que é pai de meus 3 filhos que também não tem o poblema, né (F3).

Entende-se que, para a cuidadora, a aceitação é algo necessário em seu existir no mundo, pois é preciso acostumar-se em conviver com uma criança com Aids na comunidade familiar. A aceitação de si e do outro é fundamental para que ocorra a reciprocidade na relação EU-TU; a relação somente se presentificará quando o EU estiver em sua totalidade no mundo da vida, bem como quando o TU também o estiver e, assim, pode-se compreender que a aceitação é um dos princípios que fundamentam este encontro existencial. ${ }^{5}$

O aceitar a si e à criança com Aids significa, para a cuidadora, um passo importante na continuidade de sua existência. Além disso, a aceitação é essencial para que possa vivenciar e experienciar as lutas que se apresentam no cotidiano. Ao encontro destas significações como ser-no-mundo, apresenta-se o depoimento.

Isso é uma luta! Não queria que ninguém estivesse na minha pele, ainda se fosse uma neta eu concordaria até, mas duas neta é uma barra grande. Eu já deito preocupada [...] é medo que a gente tem, a gente não sabe se um dia tu vai levantar, tu vai encontrar a neta bem, porque a minha filha mais velha foi assim, eu entrei dentro de casa e encontrei morta... [silêncio] (F4).

A mulher cuidadora significa sua existencialidade e seu modo-de-ser-no-mundo como uma luta por diferentes motivos, como a luta para que a criança realize o tratamento anti-retroviral, a luta porque cria mais de uma criança que tem Aids e, as consultas são realizadas em dias diferentes, ou porque a criança apresenta problemas de saúde que causam medo e incerteza. Para o EU familiar sua convivência com o TU criança que tem Aids é uma luta constante.

A aceitação de ter Aids ou de conviver com uma criança com Aids é um sentimento que está presente no vivido pela cuidadora, porém não representa condição única para uma vida melhor. Mesmo aceitando-se e aceitando o outro que tem
Aids, dificuldades se fazem presentes no viver das familiares e que são caracterizadas por lutas que se manifestam nas diferentes situações cotidianas que experiencia. O aceitar e o lutar são importantes para que o EU familiar possa estar-com o TU criança com Aids, e, assim, consigam, mutuamente, adentrarem e presentificarem a relação existencial EU-TU.

\section{COMPREENSÕES ACERCA DO EXISTIR DA MULHER CUIDADORA DE UMA CRIANÇA COM AIDS}

Dos discursos das cuidadoras pode-se compreender que suas experiências em conviver com uma criança com Aids desvelam-se como um fenômeno que apresenta múltiplos significados e que é vivido de maneira única e singular por cada ser-no-mundo. Sua existencialidade é permeada por momentos que considera difíceis, por medos, por perdas e necessidades, bem como por vivências significativas em comunidade familiar que possibilitam, muitas vezes, aceitar e lutar por uma vida melhor ao (con)viver com o outro.

Neste sentido, entende-se que o existir da mulher cuidadora, como ser-no-mundo, é marcado por descobertas referentes à infecção pelo HIV , que estão relacionadas a si e ao outro e, conseqüentemente, à família. Muitas vezes, no descobrir da soropositividade para o HIV da criança, há uma revelação do diagnóstico individual e familiar, desvelando, assim, uma parte do vivido historicamente por esta comunidade.

Acredita-se que os primeiros momentos após a descoberta da infecção pelo vírus da Aids em um dos seres que compõem a família, assim como a descoberta de outras doenças, é um fenômeno que provoca desestruturações, é considerado difícil e lança a necessidade de uma reorganização na vida da família. Isso porque, a doença, pode ser considerada um episódio na vida do ser humano que provoca rupturas com seus referenciais, desequilibrando seu cotidiano e seu existir, forçando a família a reorganizar-se e adaptar-se ao novo momento vivido. ${ }^{13}$

Ao descobrir que a criança vive com Aids e, muitas vezes, descobrir-se também, descortina-se uma situação complexa, que gera dificuldades existenciais e que provoca mudanças que se refletem nas situações cotidianas, como a necessidade de abandonar o emprego para dedicar-se ao cuidado da criança, a necessidade de incluir nas situações cotidianas o tratamento anti-retroviral, entre outros 
aspectos. ${ }^{14}$ Para a cuidadora, a descoberta da Aids na comunidade familiar é, inicialmente, compreendida como uma situação difícil, mas que com o tempo aproxima-se do que é considerado normal, além de possibilitar o aprendizado de lições, consoante também encontrado em outro estudo. ${ }^{3}$

Então, é na relação "entre" o EU cuidadora e o TU criança com Aids que fenômenos existenciais se desvelam e passam a constituir parte das experiências como ser-no-mundo e ser-no-mundocom-o-outro. Percebe-se, desta maneira, que o EU familiar convive com o medo das perdas e da morte em sua existencialidade, tanto no que tange às perdas econômicas, da organização da família, de pessoas significantes em sua vida, quanto, e principalmente, com o medo de que o TU criança com Aids possa morrer.

Assim, o modo de ser-no-mundo da mulher cuidadora é marcado por medos e perdas que adquirem maiores significações nas vivências em relação à finitude de pessoas significativas em suas vidas e nos receios de vivenciar a morte do TU criança com Aids. Em virtude disso, a cuidadora busca, na família, reconhecimento, apoio e cuidado a fim de conseguir superar estas dificuldades que se manifestam ao estar no mundo e com-o-outro. ${ }^{2,4}$

As vivências em comunidade familiar e a relação que estabelece com o TU criança com Aids são experiências que, também, possibilitam o emergir de sentimentos entre os seres. Estes sentimentos são percebidos pelas cuidadoras das mais diversas maneiras, seja por meio do apoio que necessitam para enfrentar os momentos adversos e do vínculo que precisam estabelecer para sentirem-se protegidas, ${ }^{3,15}$ seja por meio do respeito e da cumplicidade com o outro para que não se sintam um ISSO, em virtude dos preconceitos que vivenciam.

E é em meio a estas dificuldades e necessidades, vividas e experienciadas, e que, em algumas situações, não encontra apoio e carinho, sentindo-se sozinha, a mulher cuidadora desvela sentir-se um ISSO em virtude do preconceito ainda relacionado aos seres que vivem com Aids. Este preconceito emana do modo como o EU percebe e compreende o ser com Aids, reduzindo-o a um ser que tem uma doença; esquece, então, que o ser com Aids tem uma história de vida, sentimentos, uma família, projetos para seu devir e é um ser único e singular em sua existencialidade. ${ }^{13-14}$

Sendo assim, o EU familiar a fim de protegerse e proteger o TU criança com Aids e sua família do preconceito, lança-se na busca de possibilidades que o mantenham distante do mundo do ISSO.
Dentre elas, destaca-se o pacto de silêncio existente na comunidade familiar referente à revelação do diagnóstico àquele que tem Aids e entre os demais membros. ${ }^{16} \mathrm{O}$ pacto de silêncio que existe no interior da família pode ser compreendido como uma situação que gera proteção, tanto à criança quanto aos demais familiares, no sentido de não revelar a história de vida desta família. Com isso, a cuidadora acredita estar protegida do preconceito existente no contexto social e das atitudes discriminatórias que possam se fazer presentes no existir da criança durante seu desenvolvimento como ser-no-mundo.

Ainda, a mulher cuidadora desvela que a aceitação torna mais tranqüilo e agradável o vivido em meio ao contexto da epidemia da Aids, pois há uma comunidade familiar envolvida nesta situação cotidiana. A aceitação desvela-se como uma maneira autêntica que encontra para mostrar-se ao outro e no mundo como genuinamente se apresenta, sem o viés do olhar do outro que poderia transformá-la em um ISSO. O sentimento de aceitação pode ser considerado como o princípio para um viver e conviver melhor e mais saudável, no mundo.

Então, o medo, as perdas, o apoio, o respeito, o vínculo e a disponibilidade são geradores de situações que ora ocorrem auxiliando a mulher cuidadora na aceitação e luta de sua existencialidade ao estar em relação com o TU criança com Aids, ora ocorrem dificultando seu vivido e sua expressividade como ser-no-mundo.

\section{CONSIDERAÇÕES REFLEXIVAS}

$\mathrm{Na}$ busca por compreender os significados relacionados à existencialidade da mulher cuidadora de uma criança com Aids, procurou-se desvelar fenômenos e significações que fazem parte das vivências e experiências, ao estar com o outro em dado tempo e espaço compartilhados. Acredita-se que a perspectiva fenomenológica corroborou à medida que possibilitou a apreensão dos significados e características vividas e experienciadas pelo ser em seu mundo. Além disso, permitiu desvelar a essência do fenômeno tal como se mostra, a partir da aproximação do pesquisador em relação ao ser pesquisado com a preocupação de minimizar os pré-julgamentos e os pré-conceitos, a fim de que as descrições autênticas do vivido pudessem emergir.

Desta forma, compreende-se que ser mulher cuidadora de uma criança com Aids é significado como um fenômeno complexo que faz parte de 
sua existencialidade e adentra à comunidade familiar, revelando-se por meio de dificuldades iniciais que se transformam em aprendizados e que se manifestam na convivência do EU com o TU. Ainda, é a partir da relação com o TU criança com Aids que seu existir vai modificando-se e revelando seus medos, suas angústias, seus desafios, suas necessidades de apoio e seus sentimentos de aceitação e luta frente ao vivido.

Portanto, espera-se que este estudo contribua para que os cuidadores em saúde e, mais especificamente, os cuidadores em Enfermagem lancem um outro olhar à mulher cuidadora de uma criança com Aids no intuito de perceber que há um ser humano único e singular que tem potencialidades em vir-a-ser e limitações em não-ser, e que necessita do outro para realizar-se no mundo. Espera-se, também, que possibilite aos cuidadores em Enfermagem transcender os aspectos mais práticos do cuidado e valorizar a intersubjetividade, a relação inter-humana entre o EU e o TU e o diálogo existencial entre os seres, para que, desta forma, o cuidado humanístico possa acontecer.

\section{REFERÊNCIAS}

1 Ministério da Saúde (BR). Secretaria de Políticas de Saúde. Programa Nacional de DST e AIDS. AIDS boletim epidemiológico. Brasília (DF): Ministério da Saúde; 2007.

2 Paula CC, Crossetti MGO. Existencialidade da criança com Aids: perspectivas para o cuidado de enfermagem. Esc Anna Nery. 2008 Jan; 12(1):30-8.

3 Silva RAR, Rocha VM, Davim RMB, Torres GV. Formas de enfrentamento da Aids: opinião de mães de crianças soropositivas. Rev Latino-am Enferm. 2008 Mar-Abr; 16(2):260-5.

4 Schaurich D. Ser familiar cuidadora de uma criança com Aids: compreensões à luz da filosofia de Martin Buber [dissertação]. Porto Alegre (RS): Universidade
Federal do Rio Grande do Sul. Programa de PósGraduação em Enfermagem; 2007.

5 Buber M. Eu e Tu. 5 a ed. São Paulo (SP): Moraes; 1977.

6 Buber M. Do diálogo e do dialógico. São Paulo (SP): Perspectiva; 1982.

7 Buber M. Sobre comunidade. São Paulo (SP): Perspectiva; 1987.

8 Moreira DA. O método fenomenológico na pesquisa. São Paulo (SP): Pioneira Thomson; 2002.

9 Simões SMF, Souza IEO. Um caminhar na aproximação da entrevista fenomenológica. Rev Latino-am. Enferm. 1997 Jul; 5(3):13-7.

10 Ricoeur P. Interpretações e ideologias. $4^{\mathrm{a}}$ ed. Rio de Janeiro (RJ): F. Alves; 1990.

11 Ministério da Saúde (BR), Conselho Nacional de Saúde, Comitê Nacional de Ética em Pesquisa em Seres Humanos. Resolução No .196 de 10 de outubro de 1996: diretrizes e normas regulamentadoras de pesquisa envolvendo seres humanos. Brasília (DF): Ministério da Saúde; 1997.

12 Von Zuben NA. Martin Buber: cumplicidade e diálogo. Bauru (SP): EDUSC; 2003.

13 Schaurich D, Paula CC, Padoin SMM, Motta MGC. Utilização da teoria humanística de Paterson e Zderad como possibilidade de prática em enfermagem pediátrica. Esc Anna Nery Rev Enferm. 2005 Jan; 9(1):265-70.

14 Paula CC, Crossetti MGO. O modo de cuidar no encontro com o ser-criança que convive com Aids: o experienciar da finitude e a ética. Texto Contexto Enferm. 2005 Abr-Jun; 14(2):193-201.

15 Silvera EAA, Carvalho AMP. Familiares de clientes acometidos pelo HIV/Aids e o atendimento prestado em uma unidade ambulatorial. Rev Latinoam Enferm. 2002 Nov-Dez; 10(6):813-8.

16 Padoin SMM. A possibilidade de integrar a família ao cuidado. In: Padoin SMM, Paula CC, Schaurich D, Fontoura VA, organizadores. Experiências interdisciplinares em Aids: interfaces de uma epidemia. Santa Maria (RS): UFSM; 2006. p.289-302. 